\title{
MR enterography to evaluate sub-clinical intestinal inflammation in children with spondyloarthritis
}

\author{
Matthew L Stoll ${ }^{1,2,3^{*}}$, Ashish S Patel ${ }^{1}$, Marilynn Punaro ${ }^{1,2}$ and Molly Dempsey-Robertson ${ }^{4}$
}

\begin{abstract}
Background: Magnetic resonance enterography (MRE) is an established tool to evaluate for changes associated with inflammatory bowel disease (IBD), but has not been studied in sub-clinical IBD. We sought to evaluate the use of MRE in children with spondyloarthritis (SpA), who are at risk of having sub-clinical gut inflammation.

Methods: Children with juvenile idiopathic arthritis (JIA) with evidence of intestinal inflammation as evidence by an abnormal fecal calprotectin assay were offered MRE of their intestines. Flavored sports drink containing polyethylene glycol 3350 was used as oral contrast. Glucagon was used to arrest peristalsis. Patients were imaged in the prone position on a 1.5 T scanner. Heavily T2-weighted fat-suppressed coronal and axial images using breath-hold technique were obtained, followed by post-gadolinium fat-suppressed T1-weighted gradient echo images.

Results: We recruited five children with juvenile idiopathic arthritis (JIA); four had SpA, and one had poly-articular JIA. All five had evidence of intestinal inflammation based upon a positive fecal calprotectin assay and successfully completed the MRE. Three of the studies showed findings suggestive of IBD, including thickening and contrast uptake at the terminal ileum (TI) in one child, contrast uptake of the distal ileum in another, and prominent vasa recta and mesenteric lymph nodes in the third. The child with evidence of inflammatory changes at the $\mathrm{Tl}$ underwent colonoscopy, which revealed inflammatory bowel disease limited to the $\mathrm{Tl}$.
\end{abstract}

Conclusions: MRE can be used to evaluate for subclinical IBD in children with JIA. This protocol was safe and welltolerated, and identified mild changes in three of the subjects.

Keywords: Spondyloarthritis, Juvenile idiopathic arthritis, Inflammatory bowel disease, MRI

\section{Background}

Approximately two-thirds of adults with spondyloarthritis (SpA) have inflammatory intestinal changes similar to those detected in inflammatory bowel disease (IBD) [1]. Similar findings were reported in a small pediatric study [2]. However, these studies used colonoscopy, an expensive and invasive tool and thus one that is not well suited for research studies. Studies using barium swallow and sigmoidoscopy have identified sub-clinical intestinal inflammation in lower percentages of SpA patients, suggesting decreased sensitivity in that

\footnotetext{
* Correspondence: MStoll@peds.uab.edu

'UT Southwestern Medical Center/Department of Pediatrics/5323 Harry Hines Boulevard/Dallas, TX 75390-9063, USA

Full list of author information is available at the end of the article
}

population [3,4]. Computed tomography involves significant amounts of radiation exposure, and ultrasound is limited in some centers by operator-dependence [5]. However, one potential tool that could be used safely to evaluate the intestines in children and adults with SpA is magnetic resonance enterography (MRE).

MRE is an accepted tool to diagnose and monitor IBD. Although it does not visualize early mucosal changes such as aphthous ulcerations, MRE allows for the detection of bowel wall thickening and enhancement, as well as extramural complications of IBD, including strictures, fistulas, sinus tracts, abscesses, fibro-fatty proliferation, and lymphadenopathy [5-10]. Studies in adults and children have shown MRE to be accurate in the diagnosis of IBD, distinguishing it from
C Biomed Central 
other causes of abdominal pain with sensitivity $82-96 \%$ and specificity $>90 \%$ [11-15].

These studies raise the possibility that MRE may be of benefit to screen for subclinical intestinal inflammation in SpA patients. We previously recruited children with enthesitis-related arthritis (ERA) and other subtypes of juvenile idiopathic arthritis (JIA), and obtained measurements of fecal calprotectin, a stool study that assesses the presence of inflammation based on neutrophilderived proteins that are resistant to metabolic breakdown by intestinal bacteria and can assist in differentiating inflammatory from non- inflammatory states [16]. In that study, we showed elevated fecal calprotectin levels in ERA patients, as compared to children with other JIA subtypes, as well as controls consisting of children with unrelated connective tissue diseases and non-inflammatory causes of joint pain [17]. A limitation of fecal calprotectin is that it does not provide any information as to the location of the inflammation or the presence of specific complications potentially associated with IBD. Thus, to evaluate the anatomic location and extent of sub-clinical intestinal inflammation in children potentially at higher risk of intestinal inflammation, we performed a sub-study of the above, offering MRE to JIA patients with elevated fecal calprotectin levels.

\section{Methods}

\section{Patients}

This was a prospective sub-study of fecal calprotectin levels among patients with JIA [17], diagnosed according to the International League of Associations for Rheumatology (ILAR) criteria [18]. Calprotectin levels were measured via ELISA in a commercial laboratory (ARUP, Salt Lake City, UT), with values $<50$ micrograms/gm considered negative, 50 - 120 borderline, and $\geq 121$ elevated. Inclusion criteria for the current study were a fecal calprotectin level of at least 121 micrograms/gm obtained as part of that study. Exclusion criteria were inability to cooperate with the procedure, allergy to IV contrast, renal insufficiency, MRI incompatible devices or implants, and pregnancy; in practice, the only exclusion criteria applied was inability to undergo MRI without sedation. There was no strict age cut-off, although most children under age 8 or 9 would not be expected to be able to undergo unsedated MRI. All of the JIA patients with elevated fecal calprotectin levels $(\geq$ 121 micrograms/gm) who were potentially mature enough to undergo MRI without sedation were invited to do so; of the 8 who met the inclusion criteria, 5 agreed to participate. This study was approved by the Institutional Review Board at the UT Southwestern Medical Center. Informed consent was obtained from each subject's legal guardian, and assent was obtained from each child.

\section{MR enterography}

\section{Preparation}

Patients were NPO for six hours prior to the study. We used one packet (17 gm) of polyethylene glycol 3350 (over the counter Miralax ${ }^{\circledR}$ ) dissolved in a flavored commercial sports beverage (Gatorade ${ }^{\circledR}$ ) in order to increase bowel wall distension. Over the course of 2.5 hours, they were given a total volume of $1250 \mathrm{ml}$; one quarter of the total volume was taken approximately every 30 minutes, with the final dose given 15 - 30 minutes prior to the study. To inhibit bowel peristalsis, patients were administered $0.5 \mathrm{mg}$ glucagon IV at the onset of the study; a second dose was given if the radiologist (MDR) determined that there was motion artifact suggestive of peristalsis.

\section{MR examination}

Patients were imaged in the prone position. Utilizing a body surface coil an MRI exam was acquired on a GE 1.5 Tesla (Milwaukee, WI) MR scanner. To minimize motion artifact, the patient was asked to hold his or her breath during image acquisition, and as stated above, bowel motion was reduced with the administration of glucagon. Sequences and parameters are summarized in Table 1 . The precontrast images allowed visualization of bowel wall thickening, mesenteric lymph nodes, and prominent vasa recta. IV gadolinium, $0.1 \mathrm{mmole} / \mathrm{kg}$ (max 10 mmole) of gadoteridol (Prohance; Bracco diagnostics) was then administered, and additional images were acquired for the detection of bowel enhancement suggesting active inflammation.

\section{Results and discussion \\ Patient population}

Nine subjects with JIA had elevated fecal calprotectin levels. One was incapable of undergoing unsedated MRI, and three declined to participate in the MRI study. Thus, five patients agreed to participate, and all five completed the study (Table 2). There were no obvious differences between active joint count, disease duration, or presence vs absence of gastroenterology symptoms between the five who participated and the three who did not (data not shown.) All five had JIA and had an elevated fecal calprotectin level (median 249). Four had ERA; one had poly-articular JIA. Only one (patient \# 4) had significant gastrointestinal symptoms, consisting of abdominal pain and weight loss prior to treatment with corticosteroids, although he was asymptomatic at the time of the study.

\section{MR enterography findings}

Patients \# 2 and 3 had normal studies (Figure 1.) Patient 1 revealed increased bowel wall thickness $(4 \mathrm{~mm}$; Figure 2A) and enhancement (2B) at the terminal ileum (TI). Patient 4 showed multiple mesenteric lymph nodes and 
Table 1 MRI sequences used

\begin{tabular}{|c|c|}
\hline Type & Parameters \\
\hline \multicolumn{2}{|l|}{ Pre-contrast } \\
\hline $\begin{array}{l}\text { Coronal SSFSE } \\
\text { T2w }\end{array}$ & $\begin{array}{l}\text { TR minimum 750, TE } 70 \text { 1nex, bw } 83.3 \text { 320x 224, } \\
\text { asset, zip 512, 5/0 }\end{array}$ \\
\hline $\begin{array}{l}\text { FS Coronal 2D } \\
\text { FIESTA }\end{array}$ & $\begin{array}{l}\text { TR } 6.8 \text {, TE } 2 \text { (minimum full), } 1 \text { nex, bw } 83.3 \text {, flip angle } \\
50,288 \times 256 \text {, phase fov } 0.9 \text {, asset, zip } 512 \text { „5 } 5 / 0 \text { cor } 6 \text {, } \\
0 \text { axial }\end{array}$ \\
\hline $\begin{array}{l}\text { FS Axial 2D } \\
\text { FIESTA }\end{array}$ & Same as above \\
\hline \multicolumn{2}{|l|}{ Post-contrast } \\
\hline $\begin{array}{l}\text { FS Axial 2D } \\
\text { fSPGR }\end{array}$ & $\begin{array}{l}\text { TR } 245 \text {, TE minimum, fa } 70 \text {, bw } 83.33 \text {, nex } 1,320 \times \\
160 \text {, phase fov } 0.8,5 / 0 \text { cor, } 6 / 0 \text { axial asset }\end{array}$ \\
\hline $\begin{array}{l}\text { FS Coronal 2D } \\
\text { fSPGR }\end{array}$ & Same as above \\
\hline $\begin{array}{l}\text { Coronal 3D } \\
\text { LAVA }\end{array}$ & $\begin{array}{l}\text { TR 4.2, TE 2, TI 7, fa 12, bw } 62.5,5 \mathrm{~mm} 30 \text { locs/slab, } \\
288 \times 192 \text {, asset, zip 2, fat sat }\end{array}$ \\
\hline
\end{tabular}

MRI sequences used; the length of each of the sequences ranged from 12 45 seconds. FIESTA = fast imaging employing steady state acquisition, FS = fat-suppressed, $\mathrm{FSPGR}=$ fast spoiled gradient recalled echo, LAVA = liver acquisition with volume acceleration, SSFSE $=$ single shot fast spin echo, T2W $=\mathrm{T} 2$-weighted

prominent vasa recta (Figure 3.) Patient 5 showed increased contrast uptake at the distal ileum, without thickening (Figure 4.) There was no obvious correlation between the presence or type of bowel wall inflammation and the fecal calprotectin levels.

\section{Safety}

The study was tolerated without any serious adverse events. Patient 1 had mild emesis after the second dose of glucagon. No other adverse events were reported.

\section{Patient follow-up}

The patients were followed for a median of 9.6 months (range 5.3 - 15) after the MRI. Patient 1 subsequently developed abdominal pain and was therefore referred to gastroenterology; 5 weeks after the MRE, he underwent colonoscopy, which revealed non-specific inflammatory changes limited to the TI, prompting a diagnosis of IBD. His medical management was changed from etanercept to adalimumab, in order to treat his underlying bowel disease; he subsequently has had improvement in arthritis, albeit still active at the final visit. Patient \# 4 was referred to gastroenterology but never made the appointment. Nevertheless, due to the presence of active arthritis as well as acute anterior uveitis, he was also started on adalimumab, with improvement in his arthritis symptoms, but continued to have active arthritis at the end of the follow-up period. None of the other patients underwent changes in their medical management and were doing well at the final follow-up. Patients 2, 3, and 5 were not diagnosed with IBD or other intestinal illnesses.

The primary implication of this study is in demonstrating that MRE may be a tool with which investigators can evaluate for subtle inflammatory changes in patients with SpA. The gold standard, ileocolonoscopy, is invasive and expensive, and thus not well-suited for research purposes. Fecal calprotectin levels are elevated in children with SpA [17], but they do not provide specific anatomical information within the intestines, and it appears that their levels can be increased nearly twofold by use of non-steroidal anti-inflammatory drugs $[19,20]$. Likewise, wireless capsule endoscopy (WCE) can identify subclinical changes in SpA patients [21]; however, WCE does not identify changes beyond the intestinal mucosa, and is limited by risk of obstruction.

This study also provides further exploration of the connection between intestinal inflammation and SpA. We have previously hypothesized that in children with SpA, intestinal inflammation helps maintain peripheral synovitis via mechanisms yet unclear [22]. However, the extent of inflammation need not be extensive; indeed, while the majority of patients with SpA have intestinal inflammation [1], only a minority develop frank IBD. Likewise, in our study, the MRI findings were subtle, and none showed the extensive complications previously reported in IBD patients $[9,10]$, and thus none of the patients were diagnosed with IBD on the basis of the MRI. Tumor necrosis factor (TNF) inhibitors differ in their capacity to treat established IBD, with etanercept less efficacious as compared to some of the TNF monoclonal antagonists [23,24]. It follows that they may also differ in their capacity to treat sub-clinical intestinal inflammation, such as that identified in this study. If it is indeed the case that

Table 2 Study patients

\begin{tabular}{cccccc}
\hline Patient \# & Dx & Age/sex & Disease duration (months) & Fecal calprotectin* & Medication use \\
\hline 1 & ERA & $10.8 / \mathrm{M}$ & 15 & 231 & MTX, ETA \\
2 & ERA & $16.1 / \mathrm{M}$ & 37 & 249 & None \\
3 & PJIA & $11.5 / \mathrm{F}$ & 118 & 678 & NSAID, MTX \\
4 & ERA & $10.9 / \mathrm{M}$ & 11 & 310 & NSAID, PRED, MTX \\
5 & ERA & $14.1 / \mathrm{M}$ & 12 & 171 & ETA \\
\hline
\end{tabular}

* Micrograms/gm of stool. Normal $<121$. Abbreviations: ERA = enthesitis-related arthritis, ETA = etanercept, MTX = methotrexate, NSAID = non-steroidal antiinflammatory drugs, pJIA = poly-articular juvenile idiopathic arthritis, PRED = prednisone. 


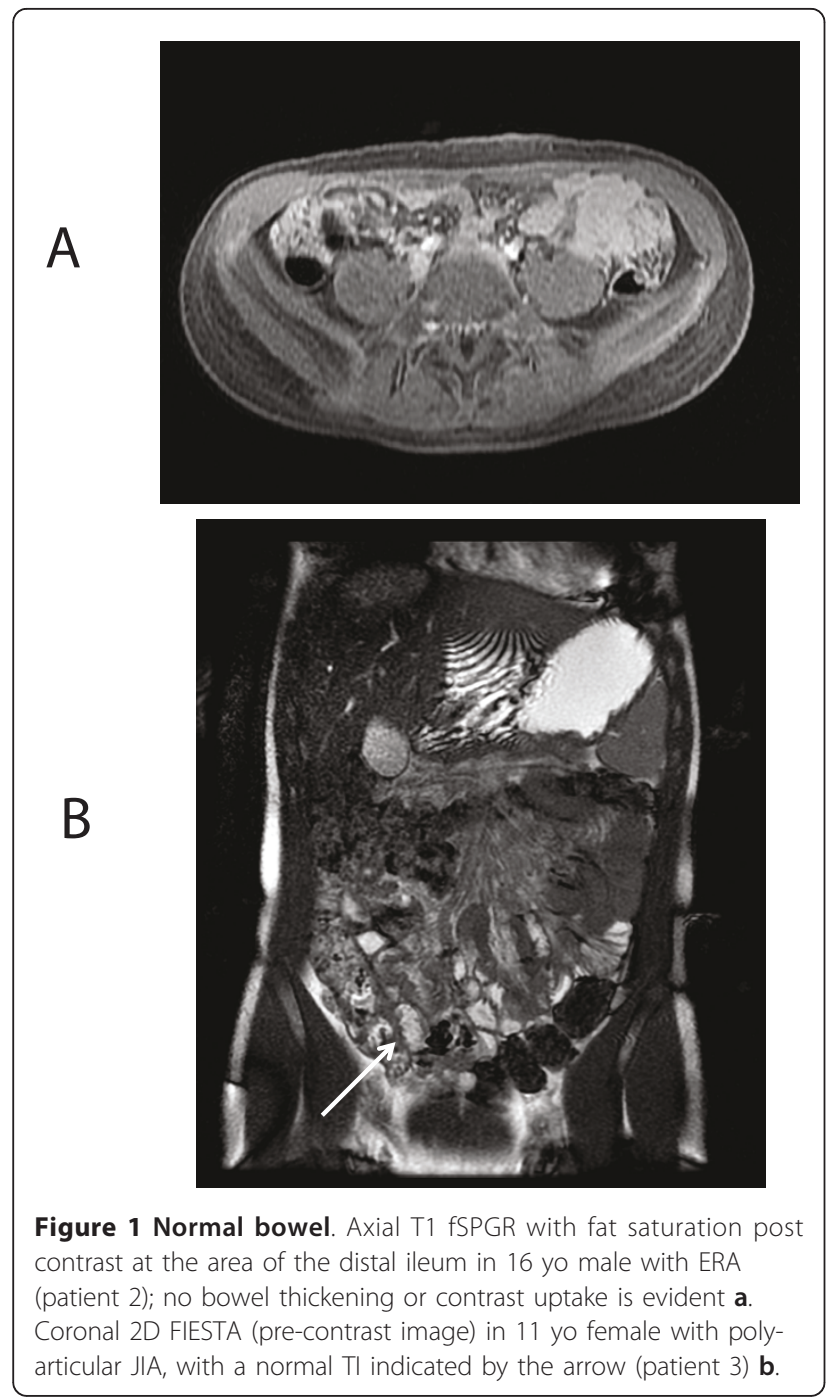

sub-clinical intestinal inflammation helps maintain peripheral arthritis in SpA, long-lasting remission may not be possible in the absence of control of this intestinal inflammation. Indeed, registry data indicates that successful withdrawal of etanercept in children with ERA is rare [25].

This study has several limitations. The sample size was small, there was no control population, and there was no gold standard study performed. Nevertheless, we believe that these findings are specific and meaningful; two of the patients had changes in the distal ileum, a common site of inflammation in IBD [26], and in one, colonoscopy confirmed inflammation at that location.

\section{Conclusions}

Magnetic resonance enterography identified subclinical intestinal inflammation in three children with spondyloarthritis. Future studies should prospectively screen newly-diagnosed children with ERA for

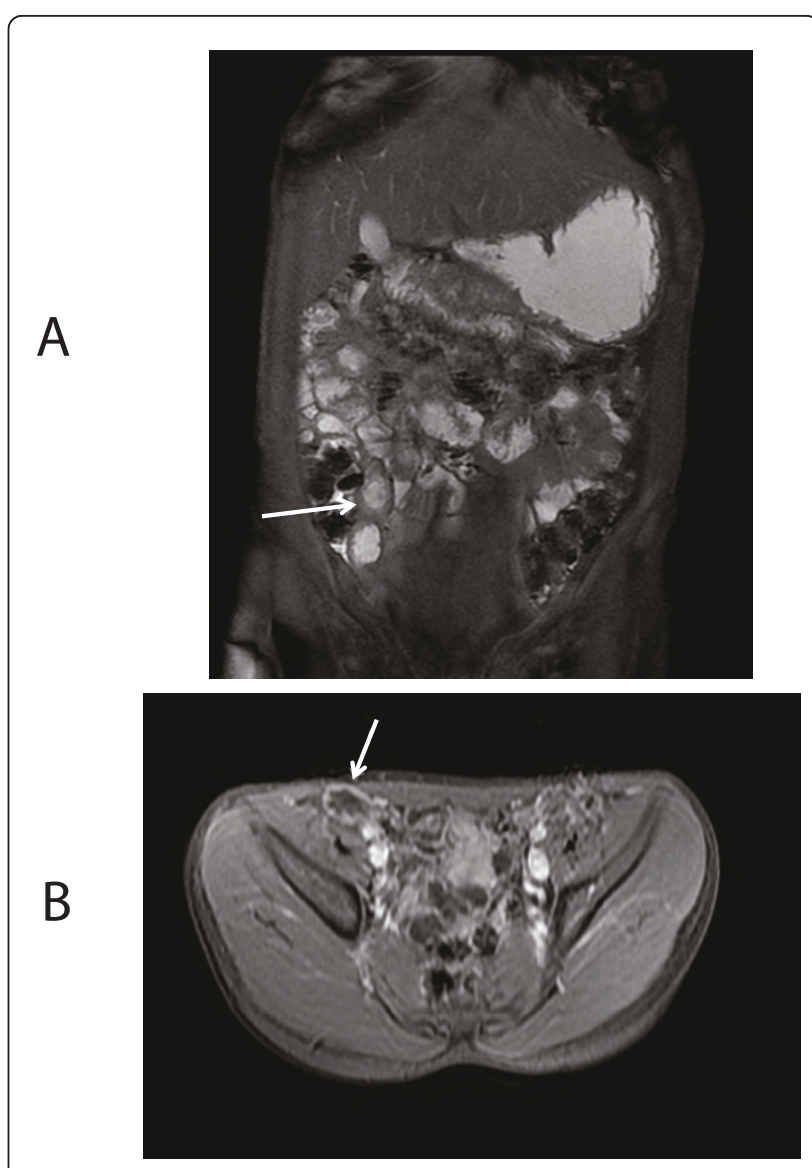

Figure 210 yo male with ERA (patient 1). Coronal 2D FIESTA with fat saturation (pre-contrast) showing thickening at the TI (arrow) a. Axial T1 fSPGR with fat saturation post-contrast showing enhancement at the terminal ileum (arrow) b.

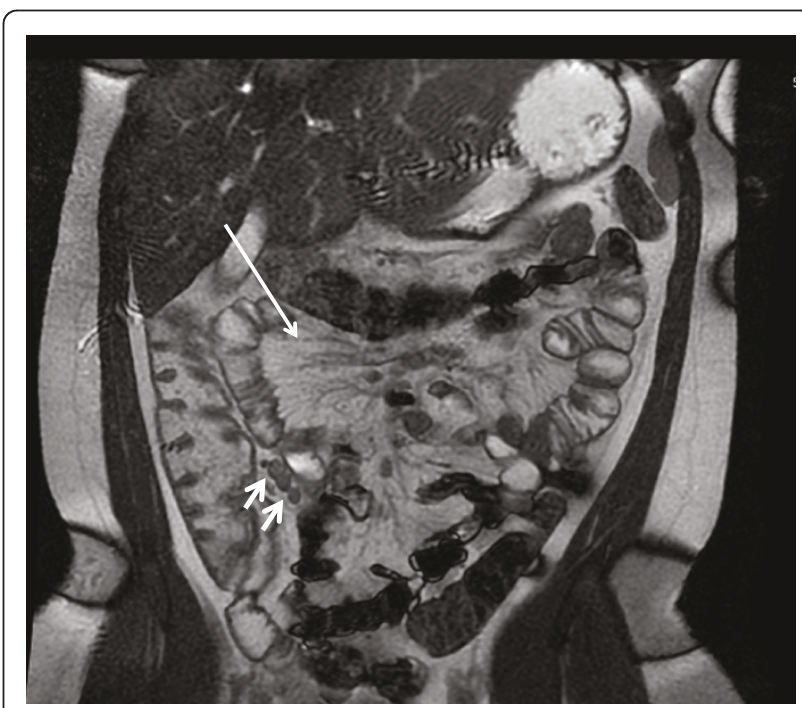

Figure 3 Another 10 yo male with ERA (Patient 4). Coronal 2D FIESTA (pre-contrast) showing prominent vasa recta (large arrow) and mesenteric lymph nodes (small arrows). The TI is not visualized on this sequence, and was normal in this patient (not shown). 


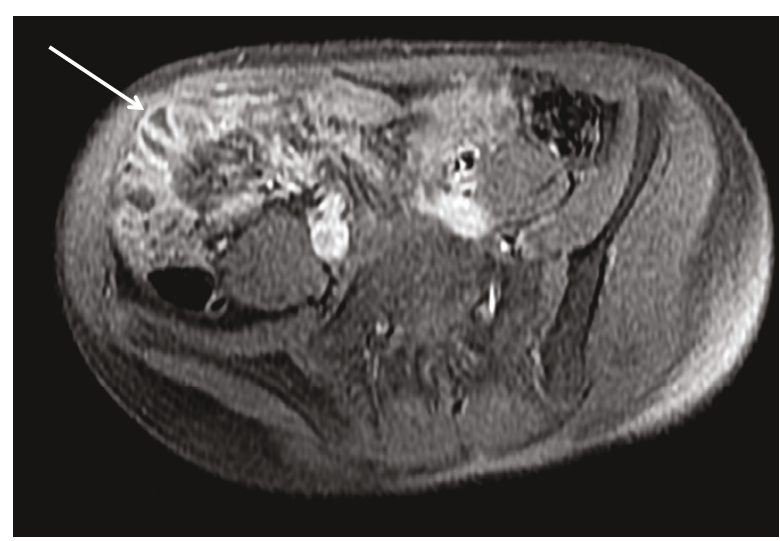

Figure 414 yo male with ERA (Patient 5). Axial T1 fSPGR with fat saturation post contrast showing abnormal enhancement at the distal ileum (arrow). There was no obvious bowel wall thickening.

intestinal inflammation with tools such as fecal calprotectin or MRE and evaluate whether or not the presence of such inflammation predicts response to anti-TNF therapy or ability to be withdrawn successfully from such therapy.

\section{List of abbreviations used}

ERA: enthesitis-related arthritis; FIESTA: fast imaging employing steady state acquisition; fSPRG: fast spoiled gradient recalled echo; IBD: inflammatory bowel disease; JIA: juvenile idiopathic arthritis; LAVA: liver acquisition with volume acceleration; MRE: magnetic resonance enterography; SpA: spondyloarthritis; TI: terminal ileum.

\section{Acknowledgements}

Dr. Stoll was supported by Grant Number UL1RR024982, titled, "North and Central Texas Clinical and Translational Science Initiative" (Milton Packer, M. D., Pl) from the National Center for Research Resources (NCRR), a component of the National Institutes of Health $(\mathrm{NIH})$ and $\mathrm{NIH}$ Roadmap for Medical Research, and its contents are solely the responsibility of the authors and do not necessarily represent the official view of the NCRR or $\mathrm{NIH}$. Information on NCRR is available at http://www.ncrr.nih.gov/.

\section{Author details}

${ }^{1}$ UT Southwestern Medical Center/Department of Pediatrics/5323 Harry Hines Boulevard/Dallas, TX 75390-9063, USA. ${ }^{2}$ Texas Scottish Rite Hospital for Children/Department of Rheumatology/2222 Welborn Street/Dallas, TX 75219, USA. ${ }^{3}$ Dr. Stoll: University of Alabama at Birmingham/Department of Pediatrics/Children's Park Place/1601 $4^{\text {th }}$ Ave S./Suite 210/Birmingham, AL 35233, USA. ${ }^{4}$ Texas Scottish Rite Hospital for Children/Department of Radiology/2222 Welborn Street/Dallas, TX 75219, USA.

\section{Authors' contributions}

MS - study design, patient recruitment, manuscript preparation; AP - data analysis, manuscript review; MP - study design; MDR - study design, interpretation of MR images, manuscript preparation. All authors read and approved the final manuscript.

\section{Competing interests}

The authors declare that they have no competing interests.

Received: 20 October 2011 Accepted: 8 February 2012 Published: 8 February 2012

\section{References}

1. Mielants H, Veys EM, Goemaere S, Goethals K, Cuvelier C, De Vos M: Gut inflammation in the spondyloarthropathies: clinical, radiologic, biologic and genetic features in relation to the type of histology. A prospective study. J Rheumatol 1991, 18(10):1542-51.

2. Mielants H, Veys EM, Cuvelier C, De Vos M, Goemaere S, Maertens M, Joos R: Gut inflammation in children with late onset pauciarticular juvenile chronic arthritis and evolution to adult spondyloarthropathy-a prospective study. J Rheumatol 1993, 20(9):1567-72.

3. McBride JA, King MJ, Baikie AG, Crean GP, Sircus W: Ankylosing Spondylitis and Chronic Inflammatory Diseases of the Intestines. Br Med J 1963, 2(5355):483-6

4. Costello PB, Alea JA, Kennedy AC, McCluskey RT, Green FA: Prevalence of occult inflammatory bowel disease in ankylosing spondylitis. Ann Rheum Dis 1980, 39(5):453-6.

5. Tolan DJ, Greenhalgh R, Zealley IA, Halligan S, Taylor SA: MR enterographic manifestations of small bowel Crohn disease. Radiographics 2010, 30(2):367-84.

6. Bernstein CN, Greenberg H, Boult I, Chubey S, Leblanc C, Ryner L: A prospective comparison study of MRI versus small bowel follow-through in recurrent Crohn's disease. Am J Gastroenterol 2005, 100(11):2493-502.

7. Mann EH: Inflammatory bowel disease: imaging of the pediatric patient. Semin Roentgenol 2008, 43(1):29-38.

8. Lin MF, Narra V: Developing role of magnetic resonance imaging in Crohn's disease. Curr Opin Gastroenterol 2008, 24(2):135-40.

9. Frokjaer JB, Larsen E, Steffensen E, Nielsen AH, Drewes AM: Magnetic resonance imaging of the small bowel in Crohn's disease. Scand J Gastroenterol 2005, 40(7):832-42.

10. Torkzad MR, Ullberg U, Nystrom N, Blomqvist L, Hellstrom P, Fagerberg UL: Manifestations of small bowel disease in pediatric Crohn's disease on magnetic resonance enterography. Inflamm Bowel Dis 2011.

11. Laghi A, Borrelli O, Paolantonio P, Dito L, Buena de Mesquita M, Falconieri $P$, Cucchiara S: Contrast enhanced magnetic resonance imaging of the terminal ileum in children with Crohn's disease. Gut 2003, 52(3):393-7.

12. Darbari $A$, Sena $L$, Argani $P$, Oliva-Hemker JM, Thompson $R$, Cuffari $C$ : Gadolinium-enhanced magnetic resonance imaging: a useful radiological tool in diagnosing pediatric IBD. Inflamm Bowel Dis 2004, 10(2):67-72.

13. Borthne AS, Abdelnoor M, Rugtveit J, Perminow G, Reiseter T, Klow NE: Bowel magnetic resonance imaging of pediatric patients with oral mannitol MRI compared to endoscopy and intestinal ultrasound. Eur Radio/ 2006, 16(1):207-14

14. Magnano G, Granata C, Barabino A, Magnaguagno F, Rossi U, Calevo MG, Toma P: Polyethylene glycol and contrast-enhanced MRI of Crohn's disease in children: preliminary experience. Pediatr Radiol 2003, 33(6):385-91.

15. Horsthuis K, Bipat S, Bennink RJ, Stoker J: Inflammatory bowel disease diagnosed with US, MR, scintigraphy, and CT: meta-analysis of prospective studies. Radiology 2008, 247(1):64-79.

16. Tibble J, Teahon K, Thjodleifsson B, Roseth A, Sigthorsson G, Bridger S, Foster R, Sherwood R, Fagerhol M, Bjarnason I: A simple method for assessing intestinal inflammation in Crohn's disease. Gut 2000, 47(4):506-13.

17. Stoll ML, Punaro M, Patel AS: Fecal Calprotectin in Children with the Enthesitis-related Arthritis Subtype of Juvenile Idiopathic Arthritis. $J$ Rheumatol 2011, 38(10):2274-5.

18. Petty RE, Southwood TR, Manners P, Baum J, Glass DN, Goldenberg J, et al: International League of Associations for Rheumatology classification of juvenile idiopathic arthritis: second revision, Edmonton, 2001. J Rheumatol 2004, 31(2):390-2.

19. Tibble JA, Sigthorsson G, Foster R, Scott D, Fagerhol MK, Roseth A, Bjarnason I: High prevalence of NSAID enteropathy as shown by a simple faecal test. Gut 1999, 45(3):362-6.

20. Meling TR, Aabakken L, Roseth A, Osnes M: Faecal calprotectin shedding after short-term treatment with non-steroidal anti-inflammatory drugs. Scand J Gastroenterol 1996, 31(4):339-44.

21. Eliakim R, Karban A, Markovits D, Bardan E, Bar-Meir S, Abramowich D, Scapa E: Comparison of capsule endoscopy with ileocolonoscopy for detecting small-bowel lesions in patients with seronegative spondyloarthropathies. Endoscopy 2005, 37(12):1165-9. 
22. Stoll ML: Interactions of the innate and adaptive arms of the immune system in the pathogenesis of spondyloarthritis. Clin Exp Rheumatol 2011, 29(2):322-30.

23. Marzo-Ortega H, McGonagle D, O'Connor P, Emery P: Efficacy of etanercept for treatment of Crohn's related spondyloarthritis but not colitis. Ann Rheum Dis 2003, 62(1):74-6.

24. Ford AC, Sandborn WJ, Khan KJ, Hanauer SB, Talley NJ, Moayyedi P: Efficacy of biological therapies in inflammatory bowel disease: systematic review and meta-analysis. Am J Gastroenterol 2011, 106(4):644-59, quiz 660.

25. Otten MH, Prince FH, Twilt M, Ten Cate R, Armbrust W, Hoppenreijs EP, Koopman-Keemink Y, Wulffraat NM, Gorter SL, Dolman KM, Swart JF, van den Berg JM, van Rossum MA, van Suijlekom-Smit LW: Tumor necrosis factor-blocking agents for children with enthesitis-related arthritis-data from the dutch arthritis and biologicals in children register, 1999-2010. $J$ Rheumatol 2011, 38(10):2258-63.

26. Caprilli R: Why does Crohn's disease usually occur in terminal ileum? J Crohns Colitis 2008, 2(4):352-6.

doi:10.1186/1546-0096-10-6

Cite this article as: Stoll et al:: MR enterography to evaluate sub-clinical intestinal inflammation in children with spondyloarthritis. Pediatric

Rheumatology 2012 10:6.

\section{Submit your next manuscript to BioMed Central} and take full advantage of:

- Convenient online submission

- Thorough peer review

- No space constraints or color figure charges

- Immediate publication on acceptance

- Inclusion in PubMed, CAS, Scopus and Google Scholar

- Research which is freely available for redistribution

Submit your manuscript at www.biomedcentral.com/submit 